$1-1-2015$

\title{
CD4 Deficit and Tuberculosis Risk Persist With Delayed Antiretroviral Therapy: 5-Year Data From CIPRA HT-001
}

\author{
S. E. Collins \\ Weill Cornell Medical College
}

M.A. Jean Juste

Groupe Haitien d'Etude du Sarcome de Kaposi et des Infections Opportunistes

S. P. Koenig

Brigham and Women's Hospital

R. Secours

Groupe Haitien d'Etude du Sarcome de Kaposi et des Infections Opportunistes

Folpowherrestinatu additional works at: https://engagedscholarship.csuohio.edu/scimath_facpub Weill Cornell Medical College

Part of the Mathematics Commons

How does access to this work benefit you? Let us know!

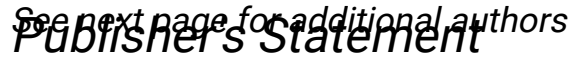

@2015 The Union. http://www.ingentaconnect.com/content/iuatld/ijtld/2015/00000019/

00000001/art00010

\section{Repository Citation}

Collins, S. E.; Juste, M.A. Jean; Koenig, S. P.; Secours, R.; Ocheretina, O.; Bernard, D.; Riviere, C.; Calnan, M.; Dunning, A.; Hurtado Rua, Sandra M.; Johnson, W. D. Jr.; Pape, J. W.; Fitzgerald, D. W.; and Severe, P., "CD4 Deficit and Tuberculosis Risk Persist With Delayed Antiretroviral Therapy: 5-Year Data From CIPRA HT-001" (2015). Mathematics Faculty Publications. 169.

https://engagedscholarship.csuohio.edu/scimath_facpub/169

This Article is brought to you for free and open access by the Mathematics and Statistics Department at EngagedScholarship@CSU. It has been accepted for inclusion in Mathematics Faculty Publications by an authorized administrator of EngagedScholarship@CSU. For more information, please contact library.es@csuohio.edu. 


\section{Authors}

S. E. Collins, M.A. Jean Juste, S. P. Koenig, R. Secours, O. Ocheretina, D. Bernard, C. Riviere, M. Calnan, A. Dunning, Sandra M. Hurtado Rua, W. D. Johnson Jr., J. W. Pape, D. W. Fitzgerald, and P. Severe 


\title{
CD4 deficit and tuberculosis risk persist with delayed antiretroviral therapy: 5-year data from CIPRA HT-001
}

\author{
S. E. Collins, M. A. Jean Juste, S. P. Koenig, R. Secours, O. Ocheretina, D. Bernard, C. Riviere, M. \\ Calnan, A. Dunning, S. M. Hurtado Rúa, W. D. Johnson Jr, J. W. Pape, D. W. Fitzgerald, P. Severe
}

SETTING: Port-au-Prince, Haiti.

O B JECTIVE: To determine long-term effects of early vs. delayed initiation of antiretroviral therapy (ART) on immune recovery and tuberculosis (TB) risk in human immunodeficiency virus (HIV) infected individuals.

DESIGN : Open-label randomized controlled trial of immediate ART in HIV-infected adults with CD4 counts between 200 and 350 cells $/ \mathrm{mm}^{3}$ vs. deferring ART until the CD4 count was $<200$ cells $/ \mathrm{mm}^{3}$. The primary comparisons were $\mathrm{CD} 4$ counts over time and risk for incident TB, with 5 years of follow-up.

RESULTS: A total of 816 participants were enrolled, with 408 in each treatment arm. The early treatment group started ART within 2 weeks, while the deferred treatment group started ART a median of 1.3 years after

FOR HUMAN IMMUNODEFICIENCY VIRUS (HIV) infected patients with CD4 counts $<350$ cells/ $\mathrm{mm}^{3}$, early initiation of antiretroviral therapy (ART) improves survival, reduces the risk of HIV transmission, and prevents opportunistic infections. ${ }^{1-4}$ The randomized Comprehensive Program for Research in AIDS (CIPRA) HT-001 trial in Haiti demonstrated that starting ART with a CD4 count between 200 and 350 cells $/ \mathrm{mm}^{3}$ reduced mortality by $75 \%$ compared to delaying ART until the CD4 count was $<200$ cells/ $\mathrm{mm}^{3}$ or an acquired immune-deficiency syndrome (AIDS) defining illness occurred, with the majority of deaths occurring before initiation of ART. ${ }^{5}$ Based on accumulated evidence from this trial and others, the World Health Organization (WHO) revised their guidelines in 2010, raising the CD4 threshold for ART initiation to $\leqslant 350$ cells $/ \mathrm{mm}^{3}$, and again in 2013 to $\leqslant 500$ cells $/ \mathrm{mm}^{3}, 6,7$

SEC and MAJJ contributed equally to this article. enrollment. After 5 years, the mean CD4 count in the early treatment group was significantly higher than in the deferred treatment group (496 cells $/ \mathrm{mm}^{3}, 95 \%$ confidence interval [CI] $477-515$ vs. 373 cells $/ \mathrm{mm}^{3}$, $95 \%$ CI 357-389; $P<0.0001)$. TB risk was higher in the deferred treatment group (unadjusted HR 2.41, $95 \% \mathrm{CI}$ 1.56-3.74; $P<0.0001$ ) and strongly correlated with lower CD4 counts in time-dependent multivariate analysis.

CONCLUSION: Delays in ART initiation for HIVinfected adults with CD4 counts of 200-350 cells $/ \mathrm{mm}^{3}$ can result in long-term immune dysfunction and persistent increased risk for TB.

KEY WORDS: human immunodeficiency virus; TB incidence; CD4 lymphocyte count; HIV-TB; ART

It is not known if and for how long after ART initiation patients who delay therapy have an immune deficit and increased risk of tuberculosis (TB). Observational studies suggest that individuals with low CD4 counts at ART initiation have impaired immunologic recovery on therapy, and low CD4 counts are the strongest mediator of TB risk. ${ }^{8-12}$ To determine the effect of early ART on CD4 recovery and $\mathrm{TB}$ risk, we conducted a study of the randomized controlled CIPRA HT-001 cohort of HIV-infected adults who received early vs. deferred ART. The primary comparisons were CD4 count and risk of incident TB over 5 years of follow-up.

\section{STUDY POPULATION AND METHODS}

\section{Design and setting}

CIPRA HT-001 was an open-label randomized controlled trial conducted at the Center of the Haitian Group for the Study of Kaposi's Sarcoma and 
Opportunistic Infections (GHESKIO) in Port-auPrince, Haiti, and was approved by the institutional review boards at GHESKIO and Weill Cornell Medical College, New York, NY, USA. All participants provided written informed consent.

Between August 2005 and July 2008, HIV-infected participants aged $\geqslant 18$ years, with a CD4 count between 200 and 350 cells $/ \mathrm{mm}^{3}$, no history of an AIDS-defining illness (WHO Stage 4), and no prior ART were enrolled. ${ }^{13}$ Pulmonary TB was not an exclusion criterion. Participants were randomly assigned to initiate ART within 2 weeks of enrollment (early treatment group), when their CD4 count was $<200$ cells $/ \mathrm{mm}^{3}$, or when they developed an AIDSdefining illness (deferred treatment group). In June 2009, a scheduled interim analysis showed a survival benefit for early ART, and the Data Safety and Monitoring Board (DSMB) recommended that all participants start ART with continued follow-up. The 2009 analysis and details on study design have been reported previously. ${ }^{5}$

In the present study, we extended follow-up until 1 January 2012 and examined the effect of early ART on $\mathrm{CD} 4$ counts and incident $\mathrm{TB}$ for 5 years after randomization.

\section{Study intervention}

Participants in both groups were seen monthly by a clinician and received an identical package of services provided to all HIV-infected patients at GHESKIO, including prophylaxis with trimethoprim-sulfamethoxazole, nutritional support and adherence counseling. ${ }^{14-17}$ Enrollees were screened for latent tuberculous infection (LTBI) and active TB using a purified protein derivative (PPD) skin test, chest Xray (CXR) and three sputum smears for acid-fast bacilli (AFB) and mycobacterial culture. Participants with a positive PPD $(\geqslant 5 \mathrm{~mm})$ were prescribed isoniazid (INH) daily for 12 months. ${ }^{18}$

ART was initiated with lamivudine, zidovudine and efavirenz, with substitutions as previously described. ${ }^{5}$ Participants in the deferred treatment group who had not met the study criteria for initiating ART by June 2009 were started on ART at the recommendation of the DSMB. Monthly clinician visits, laboratory follow-up and data collection continued with both groups on ART until 1 January 2012.

\section{Laboratory measurements}

CD4 counts were performed at enrollment and repeated every 6 months. Routine laboratory monitoring included complete blood count, aspartate transaminase (serum glutamic oxaloacetic transaminase), alanine aminotransferase (serum glutamic pyruvic transaminase) and creatinine. ${ }^{5}$

For diagnosis of TB, early morning sputum samples smears were collected and prepared using a modified
Ziehl-Neelsen stain and examined with light microscopy. Samples underwent culture for Mycobacterium tuberculosis using the BACTEC MGIT 960 system (BD, Franklin Lakes, NJ, USA). ${ }^{19}$

\section{Tuberculosis definitions}

Incident $\mathrm{TB}$ was the primary clinical end-point. Participants with symptoms suggestive of TB were screened using CXR and three sputum samples for AFB smear and mycobacterial culture. ${ }^{20}$ For suspected extra-pulmonary TB, a biopsy with AFB smear, mycobacterial culture, and histopathology was performed at the discretion of the study physician.

We used the TB case definition of the American Thoracic Society as described in previous reports. ${ }^{21,22}$ For diagnosis, the required criteria were symptoms of active TB, including fever, night sweats, weight loss, cough, dyspnea, hemoptysis, or lymphadenopathy and AFB on sputum smear, a positive culture for $M$. tuberculosis, or histopathological findings consistent with mycobacterial disease. For cases with negative AFB smear, culture and histopathology, we required a CXR highly suggestive of active TB and clinical response to anti-tuberculosis treatment. Cases were defined as microbiologically confirmed if AFB smear or M. tuberculosis culture was positive. ${ }^{23}$

Patients with active TB were treated using directly observed therapy with daily rifampin $(\mathrm{R})$, isoniazid $(\mathrm{H})$, ethambutol $(\mathrm{E})$, and pyrazinamide $(\mathrm{Z})$ for 2 months, followed by daily RH for 4 months. Patients who were retreated due to recurrence, treatment failure, or default with drug-susceptible M. tuberculosis received streptomycin plus RHEZ. ${ }^{22,23}$ Patients with drug-resistant $\mathrm{TB}$ were treated according to WHO guidelines. ${ }^{24}$

\section{Statistical analysis}

Clinical and laboratory information were entered electronically in Haiti, managed by Frontier Science and Technology Research Foundation and exported into SAS (Statistical Analysis System, Cary, NC, USA) for analysis. Analyses were based on intention to treat.

Mean CD4 counts and 95\% confidence intervals (CIs) were plotted over 24-week intervals for each treatment group, starting from randomization and separately from initiation of ART. If a participant had more than one CD4 measurement over a 24 -week period, the lower value was incorporated. Multiple imputations were used for missing data. The most conservative models using weighted averages are reported. Generalized estimating equations (GEE) were used to compare mean CD4 counts and the rate of change in CD4 counts of the two treatment groups.

For analysis of time to occurrence of incident TB, we excluded participants with active TB at enrollment. Primary data analysis was conducted from the time of randomization and a secondary analysis from 
the time of ART initiation. The outcome of interest was TB diagnosis. Participants were censored on the date they were lost to follow-up, died, or on 1 January 2012. The probability of TB-free survival was calculated using Kaplan-Meier survival methods, and differences were evaluated using the log-rank test. ${ }^{25}$ Incidence rates were compared using Fisher's exact test.

We examined previously reported predictors of TB, including time-independent variables (age at randomization, sex, education, income, PPD status, history of $\mathrm{TB})$ and time-dependent variables (CD4 count, body mass index $[\mathrm{BMI}])$ using univariate Cox proportional hazards regression models to estimate the risk of $\mathrm{TB}$ as hazard ratios (HRs) with $95 \% \mathrm{CI}$ from the time of enrollment. ${ }^{11,26}$ Variables with $P \leqslant 0.05$ in univariate analysis were retained in multivariate models. We hypothesize that the CD4 count lies on the causal pathway between ART and TB risk; we therefore analyzed models with and without treatment group as a predictor variable. Two-sided tests were adopted for all statistical inferences.

\section{RESULTS}

\section{Study participants}

Of the 1066 subjects screened, 816 were enrolled between August 2005 and July 2008. The median age was 40 years; $470(58 \%)$ were women, and the median CD4 count was 281 cells $/ \mathrm{mm}^{3}$. Forty-three had $\mathrm{TB}$ at randomization, $28(7 \%)$ in the early treatment group and $15(4 \%)$ in the deferred treatment group $(P=0.042)$. The proportion of participants with a history of TB and those with a positive PPD were balanced between the groups (Table 1).

\section{Status at time of analysis}

Data were collected until 1 January 2012. The median follow-up was 4.4 years (interquartile range [IQR] 3.5-5.0, 1531 person-years [py]) in the early treatment arm and 3.9 years (IQR 2.8-4.7, 1412 py) in the deferred treatment arm.

At the time of analysis, of 408 participants in the early treatment arm, $23(6 \%)$ had died, $30(7 \%)$ were lost to follow-up, and $355(87 \%)$ remained in care. Of the 408 participants in the deferred treatment arm, $41(10 \%)$ had died, $39(10 \%)$ were lost to follow-up, $4(1 \%)$ declined ART but remained in care, and 325 $(80 \%)$ remained in care and on ART (Figure 1).

In the deferred treatment arm, $351(86 \%)$ initiated ART a median of 1.3 years (IQR 1-2.1) after randomization. The median follow-up on ART was 2.5 years (IQR 2.3-3.3). After starting ART, 18 of $351(5 \%)$ died, $9(3 \%)$ were lost, and $324(93 \%)$ remained in care.
Table 1 Baseline characteristics of the study participants at randomization

\begin{tabular}{|c|c|c|}
\hline Characteristics & $\begin{array}{l}\text { Early } \\
\text { treatment } \\
\text { group } \\
n(\%) \\
\end{array}$ & $\begin{array}{l}\text { Deferred } \\
\text { treatment } \\
\text { group } \\
n(\%) \\
\end{array}$ \\
\hline $\begin{array}{l}\text { Total } \\
\text { Age, years, median }[\mathrm{IQR}] \\
\text { Female sex }\end{array}$ & $\begin{array}{l}408^{*} \\
40[3446] \\
241(59)\end{array}$ & $\begin{array}{l}408^{*} \\
39\left[\begin{array}{ll}32 & 47\end{array}\right] \\
229(56)\end{array}$ \\
\hline $\begin{array}{l}\text { Education level } \\
\text { No school } \\
\text { Primary school } \\
\text { Secondary school or more }\end{array}$ & $\begin{array}{l}133(33) \\
122(30) \\
153(38)\end{array}$ & $\begin{array}{l}120(29) \\
124(30) \\
164(40)\end{array}$ \\
\hline $\begin{array}{l}\text { Annual income }<5000 \\
\text { HTG/year (<US\$129/year) }\end{array}$ & $259(63)$ & $254(62)$ \\
\hline $\begin{array}{l}\text { Living with spouse or } \\
\text { partner }\end{array}$ & $177(43)$ & $164(40)$ \\
\hline $\begin{array}{l}\text { HIV clinical stage } \\
\text { Stage } 1 \\
\text { Stage } 2 \\
\text { Stage } 3 \\
\text { Stage } 4\end{array}$ & $\begin{array}{l}137(36) \\
192(51) \\
51(13) \\
0\end{array}$ & $\begin{array}{l}123(31) \\
221(56) \\
49(12) \\
0\end{array}$ \\
\hline $\begin{array}{l}\text { PPD positive } \\
\text { History of TB } \\
\text { Active pulmonary TB } \\
\text { CD4 count, cells/mm } \\
\quad \text { median [IQR] } \\
\text { BMl, } \mathrm{kg} / \mathrm{m}^{2} \text {, median [IQR] } \\
\text { Hemoglobin, g/dl, median } \\
\text { [IQR] }\end{array}$ & $\begin{array}{l}99(24) \\
52(13) \\
28(7) \\
280\left[\begin{array}{ll}250 & 305\end{array}\right] \\
21.3\left[\begin{array}{ll}19.6 & 23.7\end{array}\right] \\
11.5\left[\begin{array}{ll}10.3 & 12.5\end{array}\right]\end{array}$ & $\begin{array}{l}118(29) \\
50(12) \\
15(4) \\
282\left[\begin{array}{ll}250 & 310\end{array}\right] \\
21\left[\begin{array}{ll}19.2 & 23.4\end{array}\right] \\
11.4\left[\begin{array}{ll}10.3 & 12.5\end{array}\right]\end{array}$ \\
\hline
\end{tabular}

* There is no significant difference in any characteristics when patients with baseline TB were excluded.

${ }^{+}$The clinical stage of HIV was assessed according to the World Health Organization staging system that ranges from clinical stage 1 (no symptoms) to clinical stage 4 (AIDS).

${ }^{\ddagger}$ There was no significant difference in any characteristics when patients with baseline TB were excluded.

$\mathrm{IQR}=$ interquartile range; $\mathrm{HTG}=$ Haitian Gourde; HIV = human immunode ficiency virus; $\mathrm{PPD}=$ purified protein derivative; $\mathrm{TB}=$ tuberculosis; $\mathrm{BMI}=$ body mass index; $A I D S=$ acquired immune deficiency syndrome.

\section{CD4 count recovery}

Using GEE analysis, the mean CD4 count of the early treatment group was significantly higher over 5 years than that of the deferred treatment group $(P<$ 0.0001). At the time of randomization, the mean CD4 counts were the same (early treatment group, 262 cells $/ \mathrm{mm}^{3}$, 95\%CI 258-266; deferred treatment group, 264 cells $/ \mathrm{mm}^{3}, 95 \%$ CI 259-267). At 5 years, the mean CD 4 count of the early treatment group reached 496 cells $/ \mathrm{mm}^{3}$ (95\% CI 476-515), while that of the deferred treatment group reached 373 cells/ $\mathrm{mm}^{3}$ (95\% CI 357-389) (Figure 2). Multiple imputations for missing data did not significantly alter the results of this or subsequent analyses.

Using GEE analysis, the mean CD4 count of the early treatment group was significantly higher from the time of ART initiation through 3 years of followup on ART $(P<0.0001)$. In the early treatment group, the mean CD4 count rose from a baseline value of 262 cells $/ \mathrm{mm}^{3}$ to 483 cells $/ \mathrm{mm}^{3}$ (95\% CI 464-503) after 3 years of ART (Figure 3). In the 351 deferred treatment group participants who started ART, the mean CD4 count rose from 186 cells $/ \mathrm{mm}^{3}$ (95\%CI 179-193) to 


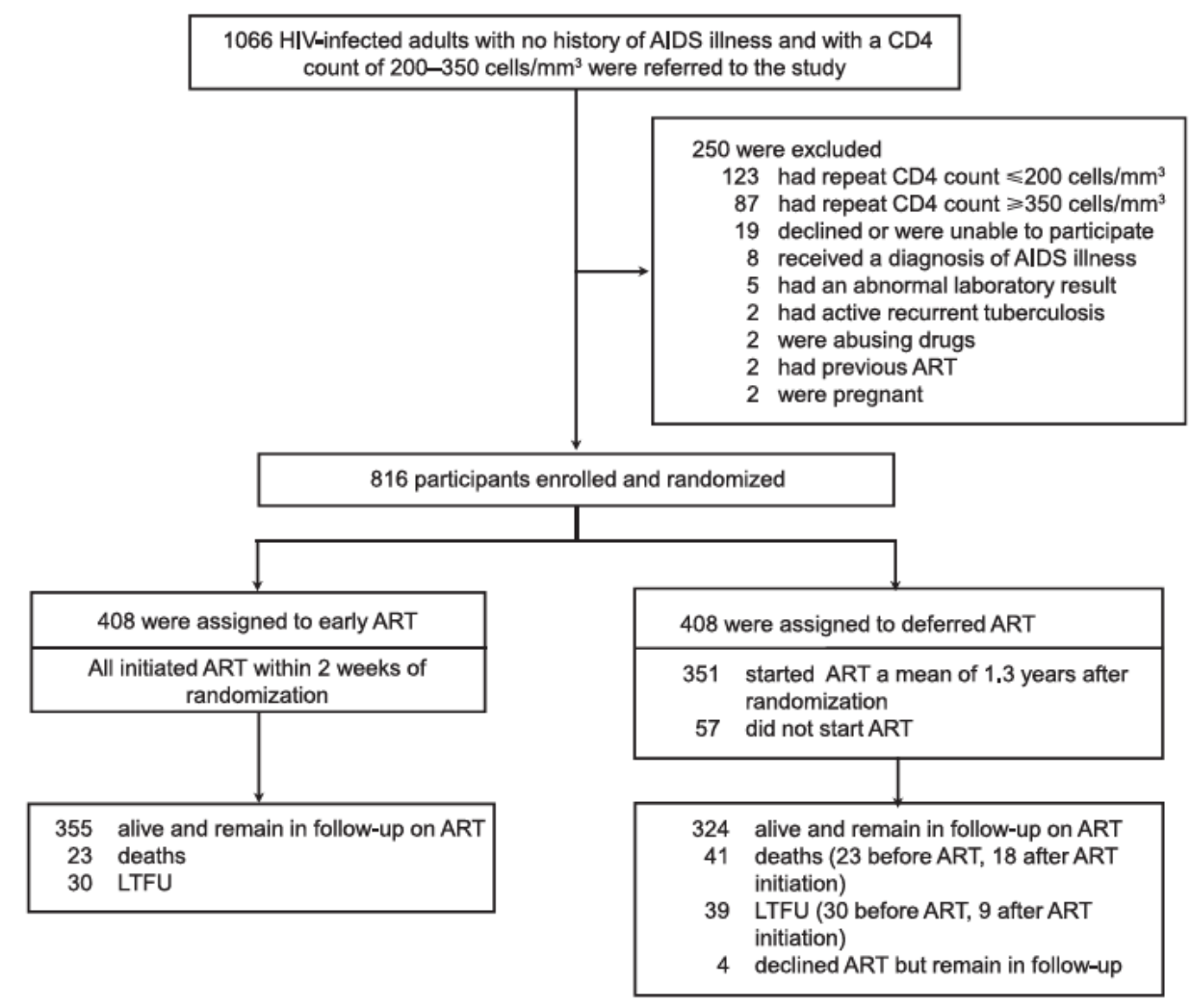

Figure 1 Study enrollment, randomization and follow-up for the early and deferred treatment groups. AIDS acquired immune-deficiency syndrome; ART antiretroviral therapy; LTFU lost to follow-up.

393 cells $/ \mathrm{mm}^{3}$ (95\% CI 374-411) after 3 years of ART. There was no difference in the rate of change of CD4 counts between groups $(P=0.47)$.

\section{Incident tuberculosis}

Forty-three $(5 \%)$ participants had active pulmonary $\mathrm{TB}$ at enrollment and were excluded from the TB incidence analysis. Among the 773 subjects who were TB-free at enrollment, 96 (12\%) developed TB during the study, 30 in the early treatment and 66 in the deferred treatment arms $(P<0.0001)$.

Among 30 early treatment group participants with TB, $29(97 \%)$ had pulmonary TB, one had extrapulmonary TB, and $14(47 \%)$ were microbiologically confirmed. Of the 66 participants in the deferred treatment group with incident TB, $33(50 \%)$ were diagnosed before starting ART and $33(50 \%)$ after starting ART. Of these, 63 (95\%) developed pulmonary TB, $3(5 \%)$ had extra-pulmonary TB, $45(68 \%)$ were microbiologically confirmed and one had multidrug-resistant TB.

In a Kaplan-Meier survival analysis from the time of randomization (Figure 4), the probability of developing TB within 5 years was $9.5 \%$ in the early treatment group compared to $20 \%$ in the deferred treatment group $(P<0.0001$ using log-rank test). Deferred ART carried an increased TB risk in the 5 years after enrollment; the unadjusted HR was 2.41 (95\% CI 1.56-3.74).

In a Kaplan-Meier survival analysis from the time of ART initiation (Figure 5), the probability of developing active TB within 3 years was $6.2 \%$ in the early treatment group compared to $11.5 \%$ in the deferred treatment group ( $P=0.026$ using log-rank test). The unadjusted HR for deferred ART was 1.69 (95\% CI 1.01-2.78).

The TB incidence rate was 2.0 cases $/ 100$ py (95\% CI 1.3-2.8) in the early treatment arm vs. 5.0 cases $/ 100$ py $(95 \%$ CI $3.9-6.2)$ in the deferred treatment arm $(P=0.001)$. In the deferred treatment group, the TB incidence rate was $6.0 / 100$ py $(95 \% \mathrm{CI}$ $4.3-8.3)$ in the pre-ART and $4.2 / 100$ py $(95 \%$ CI $3-$ 5.8 ) in the post-ART period. All participants with TB started anti-tuberculosis treatment. Two participants $(7 \%)$ in the early treatment arm and $11(17 \%)$ in the deferred treatment arm died while on anti-tuberculosis treatment.

\section{Tuberculosis risk factors}

On univariate analysis of the characteristics associated with incident $T B$, significant associations were found with treatment group, history of TB prior to enrollment, WHO HIV clinical stage at enrollment, CD4 count at the time of diagnosis and BMI at the time of diagnosis. In the multivariate model, WHO 


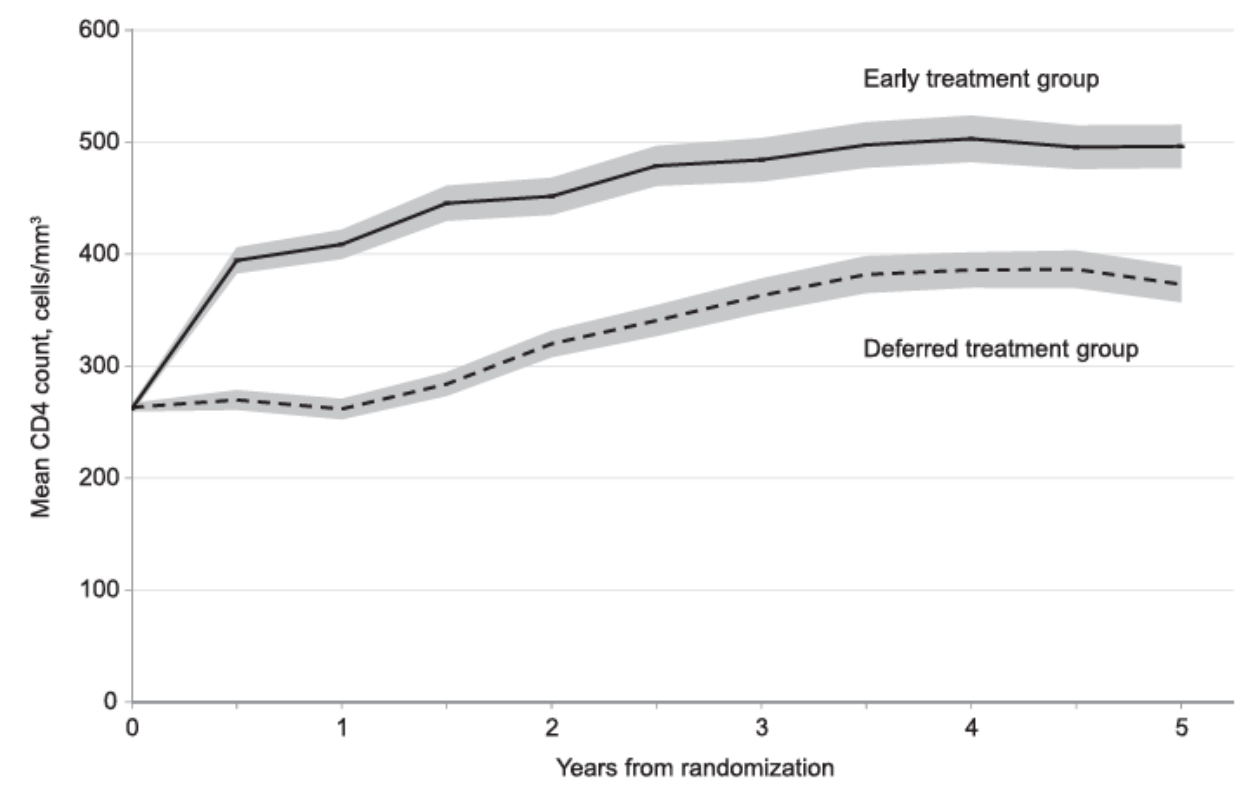

Figure 2 Mean CD4 counts over time derived from the generalized estimating equation model are plotted from the time of randomization. Shaded areas represent the $95 \%$ confidence intervals.

HIV clinical stage at enrollment, CD4 counts at diagnosis, and BMI at diagnosis were independently associated with incident TB (Table 2, Model 1). When treatment group was included in the multivariate model, both CD4 count and treatment group were significant predictors of incident TB (Table 2, Model 2). Including both variables reduced the HR for treatment group, suggesting that differences in CD4 counts mediate some, but not all, of the differential TB risk between randomization groups.

PPD status at enrollment was not significantly associated with incident TB (HR 1.27, 95\%CI $0.83-$ $1.95, P=0.28$ ). Of note, patients with a positive PPD received INH prophylaxis, and PPD status at enrollment was not a further effect modifier of the association between randomization group and TB risk.

\section{DISCUSSION}

In this randomized controlled trial, HIV-infected adults with a CD4 count of $200-350$ cells $/ \mathrm{mm}^{3}$ who

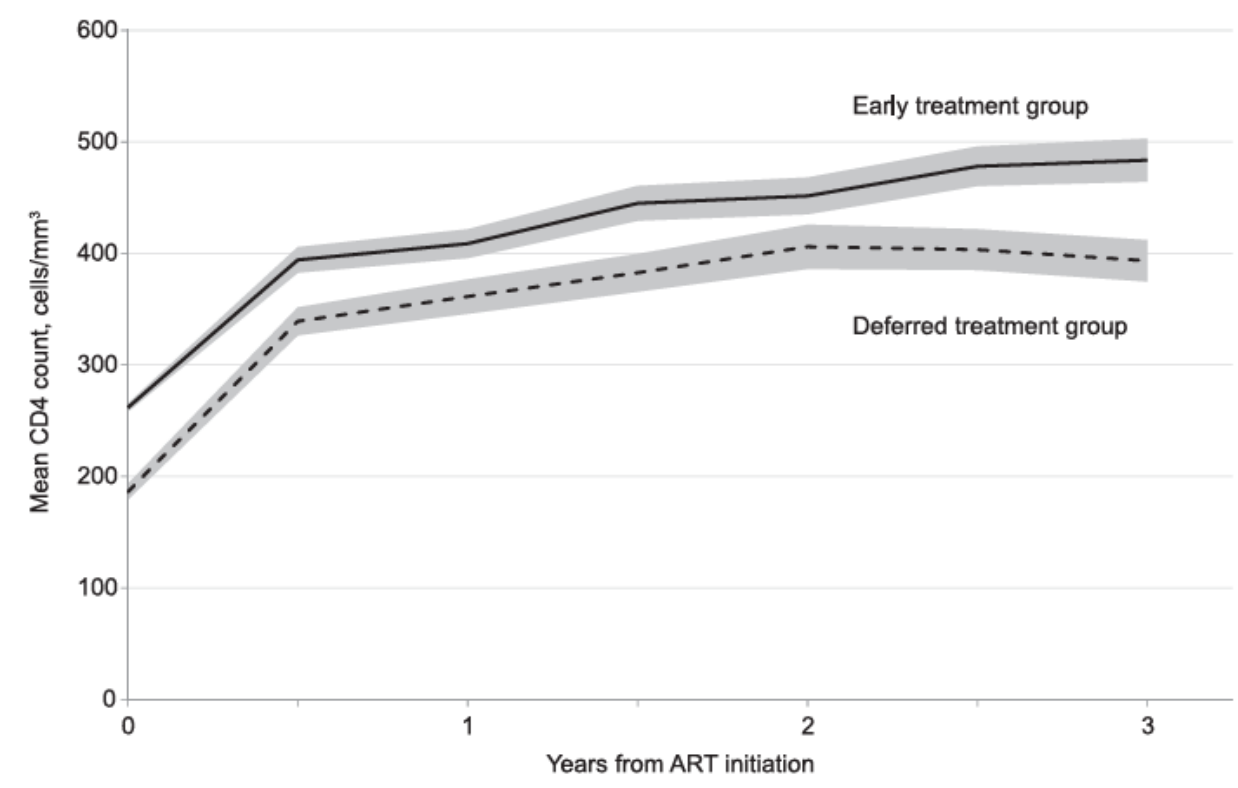

Figure 3 Mean CD4 counts over time derived from the generalized estimating equation model are plotted from the time of ART initiation. Shaded areas represent the $95 \%$ confidence intervals. ART antiretroviral therapy. 


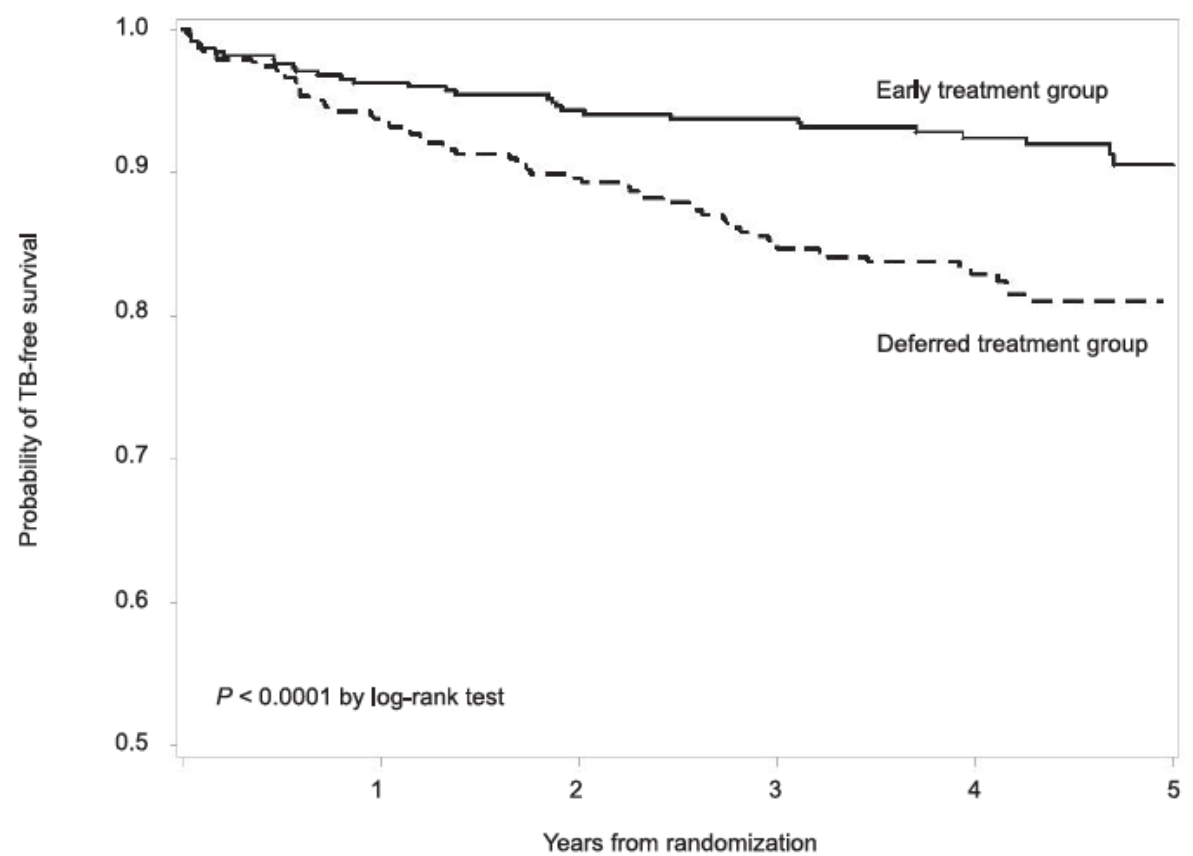

Number at risk

$\begin{array}{lllllll}\text { Early ART } & 380 & 354 & 338 & 326 & 225 & 92 \\ \text { Deferred ART } & 393 & 350 & 320 & 286 & 189 & 76\end{array}$

Figure 4 Kaplan-Meier estimates of the probability of TB-free survival from the time of study randomization. TB tuberculosis; ART antiretroviral therapy.

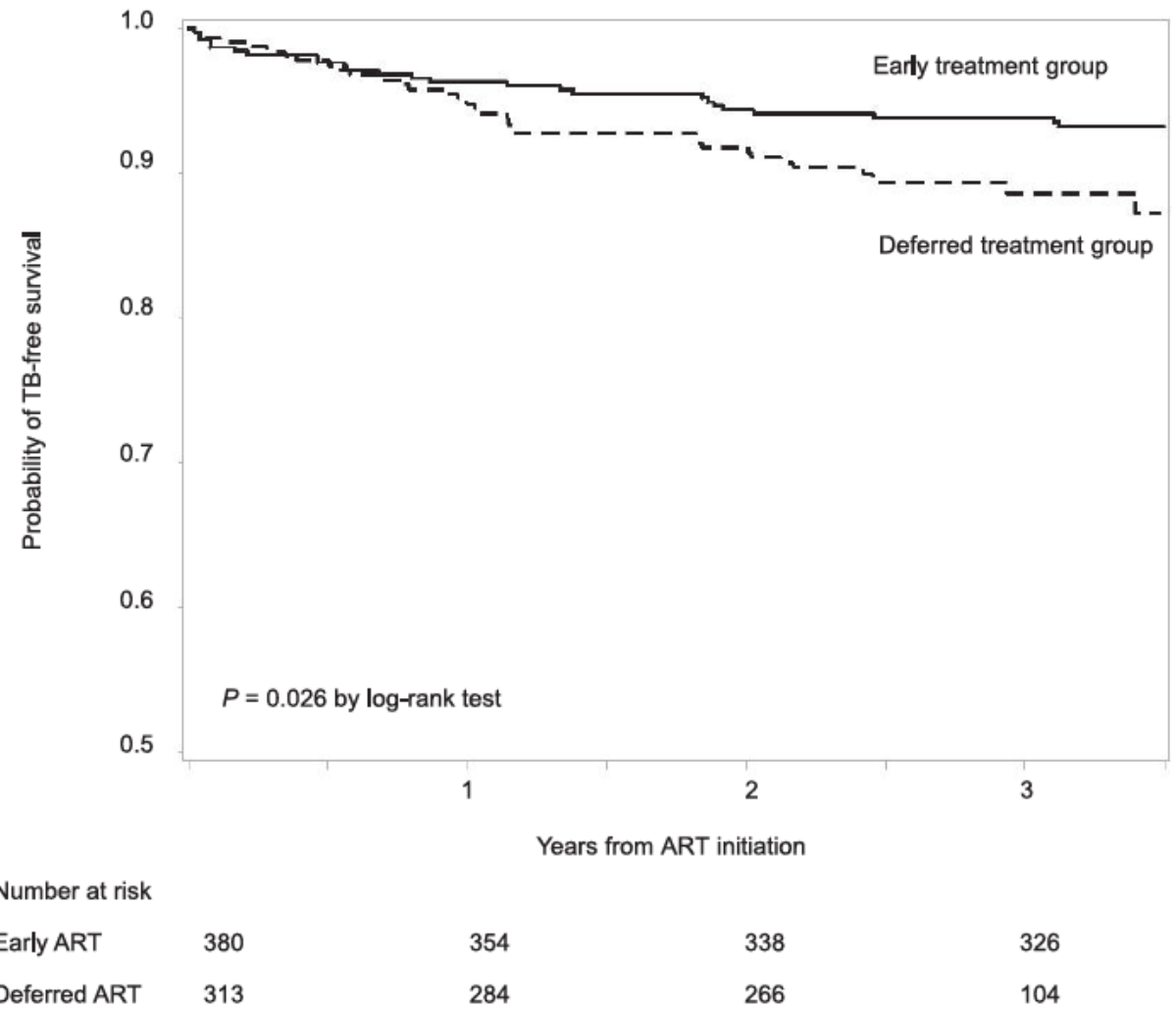

Figure 5 Kaplan-Meier estimates of the probability of TB-free survival from the time of ART initiation. TB tuberculosis; ART antiretroviral therapy. 
Table 2 Predictors of incident tuberculosis from the time of enrollment: univariate and multivariate Cox regression analyses

\begin{tabular}{|c|c|c|c|c|c|c|}
\hline \multirow[b]{2}{*}{ Variable } & \multicolumn{2}{|c|}{ Univariate } & \multicolumn{2}{|c|}{ Multivariate model 1} & \multicolumn{2}{|c|}{ Multivariate model 2} \\
\hline & $\mathrm{HR}(95 \% \mathrm{Cl})$ & $P$ value & $\mathrm{HR}(95 \% \mathrm{Cl})$ & $P$ value & $\mathrm{HR}(95 \% \mathrm{Cl})$ & $P$ value \\
\hline \multicolumn{7}{|l|}{ Baseline HIV clinical stage* } \\
\hline Stage 1 & 1.00 (reference) & & 1.00 (reference) & & 1.00 (reference) & \\
\hline Stage 2 & $1.49(0.912 .46)$ & 0.1159 & $1.28(0.772 .13)$ & 0.3450 & $1.24(0.742 .06)$ & 0.4120 \\
\hline Stage 3 & $2.62(1.434 .80)$ & 0.0018 & $2.13(1.153 .94)$ & 0.016 & $2.13(1.153 .94)$ & 0.0159 \\
\hline CD4 count (per 50 cell/ $/ \mathrm{mm}^{3}$ decrease) & $1.37\left(\begin{array}{lll}1.24 & 1.52)\end{array}\right.$ & $<0.0001$ & $1.28(1.151 .41)$ & $<0.0001$ & $1.24\left(\begin{array}{ll}1.11 & 1.38\end{array}\right)$ & $<0.0001$ \\
\hline BMI (per 1 unit decrease) & $1.20\left(\begin{array}{ll}1.13 & 1.27\end{array}\right)$ & $<0.0001$ & $1.16(1.091 .23)$ & $<0.0001$ & $1.16(1.091 .24)$ & $<0.0001$ \\
\hline \multicolumn{7}{|l|}{ Treatment group } \\
\hline Early & 1.00 (reference) & & & & 1.00 (reference) & \\
\hline Deferred & $2.41(1.563 .74)$ & $<0.0001$ & & & $1.59\left(\begin{array}{ll}1.01 & 2.52\end{array}\right)$ & 0.0471 \\
\hline Age at enrollment & $0.98(0.961 .00)$ & 0.0535 & & & & \\
\hline Sex (female vs. male) & $0.87(0.581 .31)$ & 0.4982 & & & & \\
\hline History of $\mathrm{TB}^{+}$ & $2.25(1.393 .62)$ & 0.0009 & & & & \\
\hline PPD positive & $1.27(0.831 .95)$ & 0.2781 & & & & \\
\hline Annual income <5000 HTG (US\$129) & $1.04(0.94$ 1.15) & 0.4707 & & & & \\
\hline
\end{tabular}

* The clinical stage of HIV was assessed according to the World Health Organization staging system that ranges from clinical stage 1 (no symptoms) to clinical stage 4 (AIDS).

${ }^{+}$As there was a high degree of correlation between history of TB and HIV clinical stage 3, only HIV clinical stage was used in multivariate models.

$\mathrm{HR}=$ hazard ratio; $\mathrm{Cl}=$ confidence interval; $\mathrm{HIV}=$ human immunodeficiency virus; $\mathrm{BMI}=$ body mass index; $\mathrm{TB}=$ tuberculosis; $\mathrm{PPD}=$ purified protein derivative; $\mathrm{HTG}$ $=$ Haitian Gourde; AIDS = acquired immune deficiency syndrome.

delayed ART initiation for an average of 1.3 years had a lower mean CD4 count over 5 years of followup than participants who started ART immediately. The difference between the mean CD4 counts of the treatment groups was 123 cells $/ \mathrm{mm}^{3}$ after 5 years. The TB incidence was 2.5 times higher in the deferred treatment group and correlated with lower CD4 counts. The study demonstrates that short delays in ART initiation can result in long-term immune dysfunction and increased risk of TB.

Our findings are consistent with observational cohorts in which the CD4 count at ART initiation predicts the degree of immune recovery. ${ }^{8,27-29}$ More than $75 \%$ of participants in our early treatment group achieved a CD4 count $>500$ cells $/ \mathrm{mm}^{3}$ by 5 years. When CD 4 counts are maintained above 500 cells $/ \mathrm{mm}^{3}$, mortality rates in HIV-infected individuals can approach those of the general population. ${ }^{30,31} \mathrm{In}$ contrast, $<25 \%$ of the deferred treatment group reached a CD4 count $>500$ cells $/ \mathrm{mm}^{3}$.

Early initiation of ART is cost-effective in developing countries. ${ }^{32-34}$ Our previous cost-effectiveness analysis of the CIPRA HT-001 trial did not account for the long-term impact of delayed ART on TB risk. ${ }^{34}$ The benefit of early ART will therefore likely be greater than previously estimated. In our multivariate analysis, lower CD4 counts were an independent risk factor for $\mathrm{TB}$, suggesting a causal relationship consistent with data from South Africa. ${ }^{12,35}$ These studies did not report impaired immune recovery in patients with lower CD4 counts, a finding we believe underlies the elevated TB risk in our deferred treatment participants.

PPD status was not an independent risk factor for incident TB and did not modify the effect of early ART on incident TB. Participants were enrolled when their CD4 counts were $<350$ cells $/ \mathrm{mm}^{3}$, and as a consequence already had some immune deficit. Partial anergy may explain why only $25 \%$ of the cohort was PPD-positive, when data from Haiti suggest that $60 \%$ of the population has LTBI. Furthermore, all the participants who tested PPDpositive received INH prophylaxis, which can reduce the incidence of TB by $75 \% .{ }^{18,21}$ The net effect was that PPD status was a poor predictor of incident TB in our cohort.

\section{CONCLUSION}

Relatively short delays in ART initiation for HIVinfected adults with a CD4 count of 200-350 cells/ $\mathrm{mm}^{3}$ can result in long-term immune dysfunction and increased risk of TB.

\section{Acknowledgements}

The authors thank R I Verdier, S Apollon and R Ossé for their assistance with study implementation; P Cremieux from the Analysis Group for assistance with data analysis; and Fondation Mérieux (Lyon, France) for support of laboratory training and infrastructure. This work was supported by grants from the National Institute of Allergy and Infectious Diseases at the National Institutes of Health (grant numbers AI098627, AI58257) and from the Fogarty International Center at the National Institutes of Health, Bethesda, MD, USA (grant numbers TW00018, TW009337). Additional funding was provided by the Hull Trust, Hull, UK. The funders had no role in study design, data collection and analysis, decision to publish, or preparation of the manuscript. SMHR acknowledges partial support by funds from the Clinical Translational Science Center (Weill Cornell Medical College, New York, NY, USA), National Center for Advancing Translational Sciences [grant number UL1 TR000457 06]. The content is solely the responsibility of the authors and does not necessarily represent the official views of the funding source NCATS based in Rockville, MD, USA.

ClinicalTrials.gov number NCT00120510.

Conflicts of interest: none declared. 


\section{References}

1 Cohen M S, Chen Y Q, McCauley M, et al. Prevention of HIV 1 infection with early antiretroviral therapy. N Engl J Med 2011; 365: 493505.

2 Leger P, Charles M, Severe P, Riviere C, Pape J W, Fitzgerald D W. 5 year survival of patients with AIDS receiving antiretroviral therapy in Haiti. N Engl J Med 2009; 361: 828829.

3 Ray M, Logan R, Sterne J A, et al. The effect of combined antiretroviral therapy on the overall mortality of HIV infected individuals. AIDS 2010; 24: 123137.

4 Severe P, Leger P, Charles M, et al. Antiretroviral therapy in a thousand patients with AIDS in Haiti. N Engl J Med 2005; 353 : 23252334.

5 Severe P, Juste M A, Ambroise A, et al. Early versus standard antiretroviral therapy for HIV infected adults in Haiti. N Engl J Med 2010; 363: 257265.

6 World Health Organization. Antiretroviral therapy for HIV infection in adults and adolescents: recommendations for a public health approach: 2010 revision. Geneva, Switzerland: WHO, 2010.

7 World Health Organization. Consolidated guidelines on the use of antiretroviral drugs for treating and preventing HIV infection: recommendations for a public health approach. Geneva, Switzerland: WHO, 2013.

8 Gras L, Kesselring A M, Griffin J T, et al. CD4 cell counts of 800 cells $/ \mathrm{mm}^{3}$ or greater after 7 years of highly active antiretroviral therapy are feasible in most patients starting with 350 cells $/ \mathrm{mm}^{3}$ or greater. J Acquir Immune Defic Syndr 2007; 45: 183192.

9 Lok J J, Bosch R J, Benson C A, et al. Long term increase in CD4+ T cell counts during combination antiretroviral therapy for HIV 1 infection. AIDS 2010; 24: 18671876.

10 Robbins G K, Spritzler J G, Chan E S, et al. Incomplete reconstitution of $\mathrm{T}$ cell subsets on combination antiretroviral therapy in the AIDS Clinical Trials Group protocol 384. Clin Infect Dis 2009; 48: 350361.

11 Lawn S D, Badri M, Wood R. Tuberculosis among HIV infected patients receiving HAART: long term incidence and risk factors in a South African cohort. AIDS 2005; 19: 21092116.

12 Lawn S D, Myer L, Edwards D, Bekker L G, Wood R. Short term and long term risk of tuberculosis associated with CD4 cell recovery during antiretroviral therapy in South Africa. AIDS 2009; 23: 17171725.

13 WHO case definitions for AIDS surveillance in adults and adolescents. Wkly Epidemiol Rec 1994; 69: 273 275. [English, French]

14 Peck R, Fitzgerald D W, Liautaud B, et al. The feasibility, demand, and effect of integrating primary care services with HIV voluntary counseling and testing: evaluation of a 15 year experience in Haiti, 1985 2000. J Acquir Immune Defic Syndr 2003; 33: 470475.

15 Fawzi W W, Msamanga G I, Spiegelman D, et al. A randomized trial of multivitamin supplements and HIV disease progression and mortality. N Engl J Med 2004; 351: 2332.

16 Anglaret X, Chene G, Attia A, et al. Early chemoprophylaxis with trimethoprim sulphamethoxazole for HIV 1 infected adults in Abidjan, Cote d'Ivoire: a randomised trial. Cotrimo CI Study Group. Lancet 1999; 353: 14631468.

17 Yazdanpanah Y, Losina E, Anglaret X, et al. Clinical impact and cost effectiveness of co trimoxazole prophylaxis in patients with HIV/AIDS in Cote d'Ivoire: a trial based analysis. AIDS 2005; 19: 12991308

18 Pape J W, Jean S S, Ho J L, Hafner A, Johnson W D, Jr. Effect of isoniazid prophylaxis on incidence of active tuberculosis and progression of HIV infection. Lancet 1993; 342: 268272.
19 Ocheretina O, Morose W, Gauthier M, et al. Multidrug resistant tuberculosis in Port au Prince, Haiti. Rev Panam Salúd Publica 2012; 31: 221224.

20 Burgess A L, Fitzgerald D W, Severe P, et al. Integration of tuberculosis screening at an HIV voluntary counselling and testing centre in Haiti. AIDS 2001; 15: 18751879.

21 Fitzgerald D W, Desvarieux M, Severe P, Joseph P, Johnson W D $\mathrm{Jr}$, Pape J W. Effect of post treatment isoniazid on prevention of recurrent tuberculosis in HIV 1 infected individuals: a randomised trial. Lancet 2000; 356: 14701474.

22 Blumberg H M, Burman W J, Chaisson R E, et al. American Thoracic Society/Centers for Disease Control and Prevention/ Infectious Diseases Society of America: treatment of tuberculosis. Am J Respir Crit Care Med 2003; 167: 603 662.

23 World Health Organization, Stop TB Initiative. Treatment of tuberculosis: guidelines. $4^{\text {th }}$ ed. WHO/HTM/TB/2009.420. Geneva, Switzerland: WHO, 2010.

24 World Health Organization. Guidelines for the programmatic management of drug resistant tuberculosis. WHO/HTM/TB/ 2006.361. Geneva, Switzerland: WHO, 2006.

25 Klein J P, Moeschberger M L. Survival analysis: techniques for censored and truncated data. New York, NY, USA: Springer, 2003.

26 Kufa T, Mngomezulu V, Charalambous S, et al. Undiagnosed tuberculosis among HIV clinic attendees: association with antiretroviral therapy and implications for intensified case finding, isoniazid preventive therapy, and infection control. J Acquir Immune Defic Syndr 2012; 60: e22 e28.

27 van Lelyveld S F, Gras L, Kesselring A, et al. Long term complications in patients with poor immunological recovery despite virological successful HAART in Dutch ATHENA cohort. AIDS 2012; 26: 465474.

28 Kaufmann G R, Furrer H, Ledergerber B, et al. Characteristics, determinants, and clinical relevance of CD4 $\mathrm{T}$ cell recovery to $<500$ cells/microL in HIV type 1 infected individuals receiving potent antiretroviral therapy. Clin Infect Dis 2005; 41: 361 372.

29 Hughes R A, Sterne J A, Walsh J, et al. Long term trends in CD4 cell counts and impact of viral failure in individuals starting antiretroviral therapy: UK Collaborative HIV Cohort (CHIC) study. HIV Med 2011; 12: 583593.

30 McManus H, O’Connor C C, Boyd M, et al. Long term survival in HIV positive patients with up to 15 years of antiretroviral therapy. PLOS ONE 2012; 7: e48839.

31 Lewden C, Bouteloup V, De Wit S, et al. All cause mortality in treated HIV infected adults with CD $4 \geqslant 500 / \mathrm{mm}^{3}$ compared with the general population: evidence from a large European observational cohort collaboration. Int J Epidemiol 2012; 41: 433445.

32 Bor J, Herbst A J, Newell M L, Barnighausen T. Increases in adult life expectancy in rural South Africa: valuing the scale up of HIV treatment. Science 2013; 339: 961965.

33 Johnson L F, Mossong J, Dorrington R E, et al. Life expectancies of South African adults starting antiretroviral treatment: collaborative analysis of cohort studies. PLOS MED 2013; 10: e1001418.

34 Koenig S P, Bang H, Severe P, et al. Cost effectiveness of early versus standard antiretroviral therapy in HIV infected adults in Haiti. PLOS MED 2011; 8: e1001095.

35 Gupta A, Wood R, Kaplan R, Bekker L G, Lawn S D. Tuberculosis incidence rates during 8 years of follow up of an antiretroviral treatment cohort in South Africa: comparison with rates in the community. PLOS ONE 2012; 7: e34156. 